\title{
Raw Concepts of Sustainability in Vernacular Dwellings-A Case Study of Kangbaiwan Mansion in China
}

\author{
Xiaoqing A. Song \\ Zhongyuan University of Technology, Zhengzhou, China \\ Email: singasongcs@163.com \\ Bin B. Su \\ Unitec Institute of Technology, Auckland, New Zealand \\ Email: bsu@unitec.ac.nz
}

\begin{abstract}
The building sector is one of the highest energy consuming sectors in the world as well as in China, it is urgent to seek an energy-saving way of sustainable architecture development. From the perspective of tradition, this paper focus on raw concepts of sustainability that contained in excellent vernacular dwellings. On the basis of analyzing an example of Kangbaiwan Mansion, it illustrates the advantage of environment ecosystem, and summarizes the physical and cultural characteristic of its buildings, which can be a fertile source of modern sustainable architecture design as well as a proper way of inheriting the outstanding traditional culture.
\end{abstract}

Index Terms - kangbaiwan mansion, sustainable architecture, cave dwelling, vernacular dwelling, traditional architecture

\section{THE DEVELOPMENT OF THE CONCEPT OF SUSTAINABILITY}

Facing to the environmental issues such as accumulating energy crisis and climate change in recent decades, which are not the only ecological concern that should on our list, it is becoming crucial and an inevitable option for sustainable development. Sustainability obtained attention from all walks of life, including building field.

Sustainable architecture in the past thirty years has experienced vigorous development, emerged in a number of important theories and research results. One of them is ecological architecture, which focus on the concept of man's bioclimatic approach and alternative energy strategy. Another is energy-efficient building which concentrates more on the appropriate technique adopted to lower the relative consumption of energy. The further developed concept is defined as green building: The practice of increasing the efficiency, with which buildings and their sites use energy, water, and materials, and reducing building impacts on human health and the environment, through better siting, design, construction,

Manuscript received November 9, 2015; revised January 20, 2016. operation, maintenance, and removal--the complete building life cycle [1]. With the deepening of cognition, architectural experts finally fixed their attention upon Sustaining the compatibility of architecture, human beings and the nature, which they found some of the principles just existed in the traditional architecture. It is no surprise when the essential of architecture is concerned. From its very beginning, the characteristic of architecture form has been closely related to the specific climate and topography in a certain location. That is the most basic principle appropriate not only in the ancient times but also in modern times. There are also many other concepts deserve review our vision of historical and traditional architecture, which should become a rich source for the creative design of sustainable architecture. "This was not done by the blind imitation and copy of its appearance, but through the conscious and deep understanding of esoteric principles of architecture." [2].

Taking a case study of China as an example, this article discusses the inspiration of traditional architecture for modern sustainable architecture design.

\section{The KangBaiwan Mansion In Gongyi City, HENAN PROVINCE OF CHINA}

The Kangbaiwan (a millionaire with the last name Kang) Mansion was first established in the late Ming Dynasty (AD1368 1644) and maintained till the early part of the twentieth century over a period of more than 300 years. At its peak, the relatively self-sufficient estate covered an area of $240 \mathrm{mu}(1 \mathrm{mu}=0.0667$ hectares $)$ and included not only a walled compound for the immediate family and nearby residences for other kin as well as retainers, but also ancestral worship facilities, workshop areas, inns for travelers, stables for riding, pack, and work animals, livestock pens, a brick and tile-making kiln, a military camp, and a granary and stores complex. [3]. Nowadays, with the traces of most of the ancillary structures, only the main parts of the mansions such as the walled terrace area exist and is an officially protected site in China. 


\section{A. Geographic Location and Climate}

The Kangbaiwan Mansion sits on the terminal of the Loess Plateau, along the Yiluo river, where there is the Yellow river and Mount Mangshan in the North and the Mount Songshan in the south. It's an advantaged geographical position. As a sentry, the Gongyi city next to the ancient capital-Luoyang. So, Gongyi (with the name Gongxian in the history) is the center of wars and a place with economic prosperity from the ancient times. The longitude of the city is $34^{\circ} 31^{\prime} \sim 34^{\circ} 52^{\prime}$ North, its latitude is $112^{\circ} 49^{\prime} \sim 113^{\circ} 17^{\prime}$ East.

Gongyi has a temperate and monsoonal climate with four clearly distinct seasons. It is cold in winter and hot in summer. The average annual temperature is $15.1{ }^{\circ} \mathrm{C}$, About 220 days in the year are frost-free. With the annual mean rainfall is 585 millimeters, the climate is dry (Fig. $1)$.

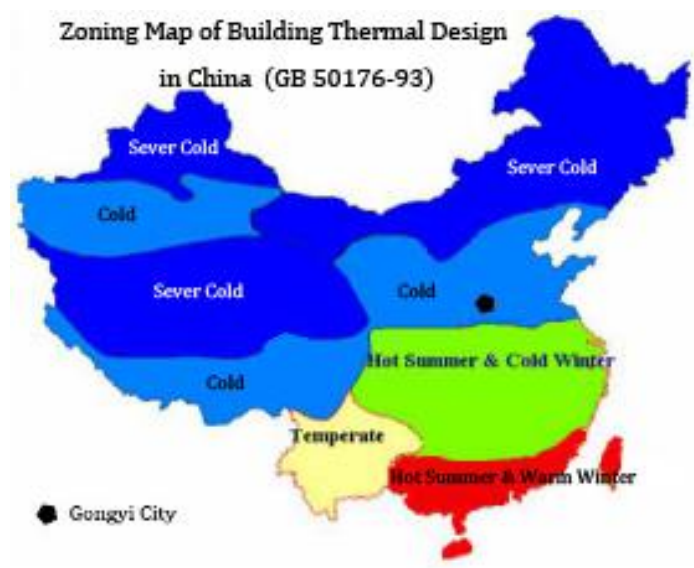

Figure 1. Building thermal design partition map of China

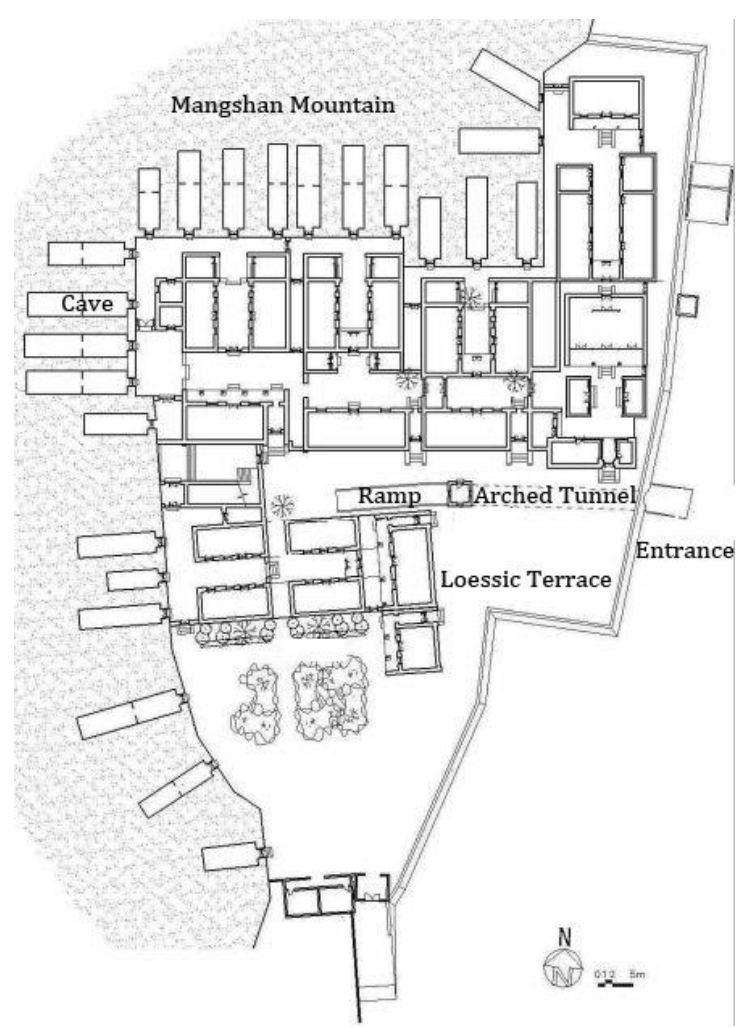

Figure 2. Plan of the main residential area of Kangbaiwan mansion

\section{B. The Overall Arrangement}

The concept of "fronting water and with hills on the back" is one of the fundamental principles of the ideal environmental pattern for residential area in the architecture tradition of China. This is a true portrayal of Kangbaiwan Mansion's environment. Clinging to the southern slope of Mangshan mountain, The main dwelling houses of the Mansions follow the lie of steep cliff and make the main orientation facing South and East, which is the best orientation to gain more passive solar heating. All the buildings situated on a loessic terrace which is 83 meters from north to south, 73 meters wide and $12 \mathrm{~m} \sim 15 \mathrm{~m}$ high from the ground. The ramp in the arched tunnel is the only access to the terrace which is surfaced by grey bricks. This ingenious measure provides a safeguard against both natural disaster such as flooding and invaders in troubled times (Fig. 2).

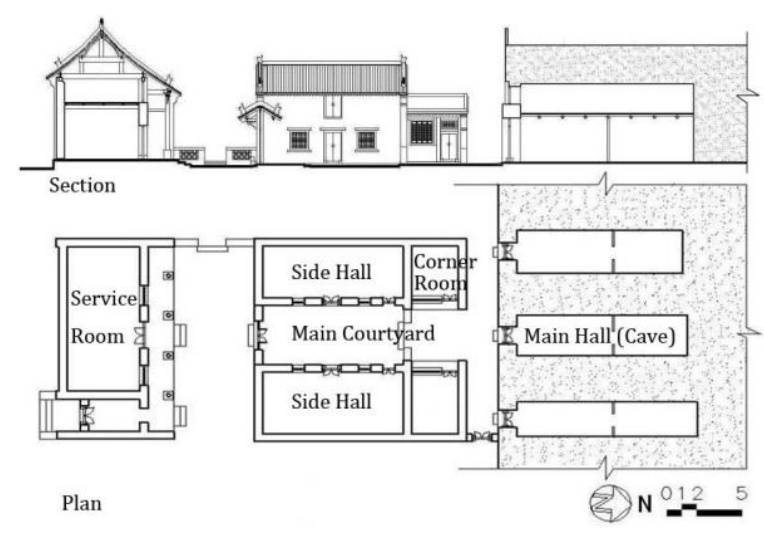

Figure 3. Environmental sketch drawing of the main residential area of Kangbaiwan Mansion

To the east of the mansions, the Yiluo river flows pass from southwest to northeast joining into Yellow River about 15 kilometers away. Such geomatic and treasured site offers the residence area to against the chill wind from northwest in winter and guarantee adequate ventilation in summer due to the specific terrain of China which is high in west and low in east. It meets the concept of "harmony between man and nature" of the Oriental philosophy, as well as the spirits of sustainability in modern times (Fig. 3).

\section{The Courtyard}

The courtyard is the fundamental unit of architectural complex in China. According to the geographic latitude, the size of yards vary very much. In general, they are wide to obtain enough solar radiation in the high latitude area and narrow to provide more shading in the low latitude area.

As for the Kangbaiwan mansion, Most of Caves were dug as the space of main hall, which form a rectangular courtyard with conventional timber framed, slope roof buildings in other three sides (Fig. 4).

With all the doors and windows face the courtyard, it becomes the central area of domesticity. Due to the latitude and mountainous topography of western part of Henan province, the mansion courtyards which only the 
central bay of the main hall can be seen from the bottom, is relatively narrow compared with the courtyard in the southern of the province which the whole facade of the main hall can be seen (Fig. 5). [4]. Based on the sunlight distribution analysis, it is easy to conclude that the scale of the narrow courtyard fulfill the basic request of solar heating, which was adopted merely followed the good tradition and builders' rich experience.

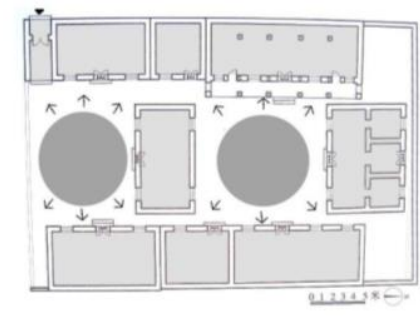

Left:

Wide Courtyard in Nanyang City, southern Henan.

Below:

Narrow Courtyard of Kangbaiwan Mansion

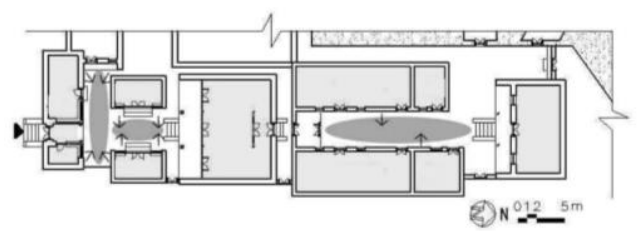

Figure 4. Typical courtyard unit of Kangbaiwan Mansion

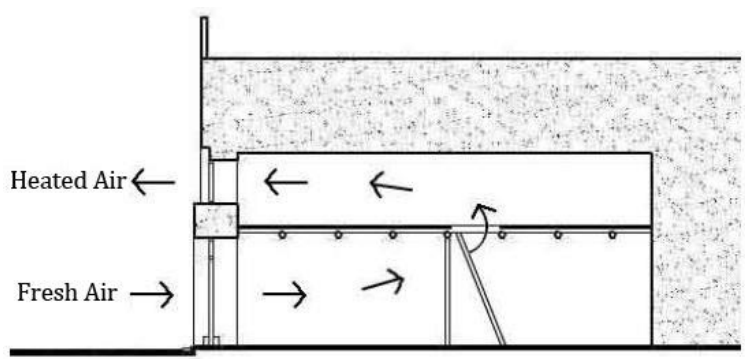

Figure 5. Comparation of two type of courtyard

Other than that, the trees and flowers planted in yards offer not only a beautiful scenery but also a necessary shading in summer.

Such two or three courtyards range in line forming a central south-north axis which is an ordinary pattern of layout of chinese tradition architecture. The more living spaces are needed, the more such axial group of buildings are built. Most of yards conform with the regulation in Kangbanwan Mansion, while a few form an east-west axis due to the lie of cliff.

\section{Concepts of Sustainability in Architecture}

Many kinds of traditional rural buildings which came into existence after a long time of evolvement can adapt to the local climate and can achieve satisfying thermal comfort. One of the most significant architectural character of Kangbaiwan mansion is the various architecture typologies that can be arranged in three classes as follows: the cliffside cave dwellings, simulated subterranean structures, and traditional post-beam structures.

Taking advantage of the special geological conditions and climate characteristics, cave-dwellings become the optimal choice for the residence living in the loess plateau area. They are relatively warm in the winter and cool in the summer, as well as cost-efficient and landsaving. The defects are the poor lighting and ventilation conditions. The significant feather of cliffside caves in the mansion is that they are two storeys. In addition, there is even a three-storey cave, which is the only one that has been known. Though the space of the second or third floor serve just as storage, the natural lighting and ventilation are improved because of the additional windows and the higher interior space (Fig. 6).

Such merits were inherited and developed in new type of cave-dwellings, which are performing well both in thermal conditions and energy saving (Fig. 7).

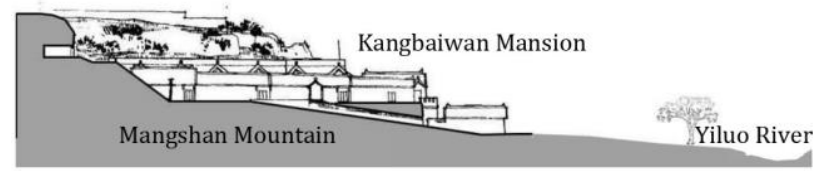

Figure 6. Ventilation analysis of two-storey cave dwelling in Kangbaiwan Mansion

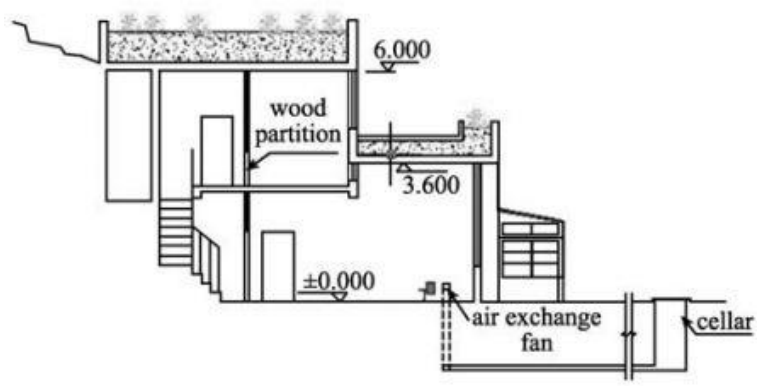

Figure 7. A new type of cave dwelling in Yan'an, Shaanxi Province [5

The same two-storey strategy was adopted in the traditional post-beam timber architectures. The storage space under the Pitched roof not only increases the usable area but also improves the insulation performance as a transition area (Fig. 8). Though designed more likely for privacy, the elaborate alcove bed is an additional compensation of thermal comfort (Fig. 9).

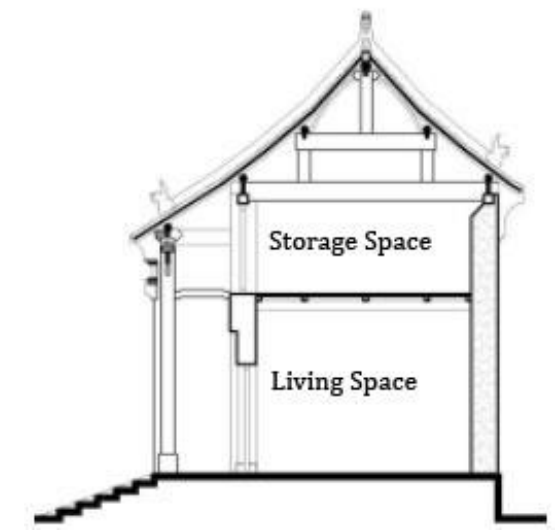

Figure 8. Storage space in the pitched roof building

Simulated subterranean structures are created to continue the benefits of caves in the area without available loess cliffs. Just as the name, they simulated the cliffside cave-dwellings by constructing the arch-roof structures and covering with soil, which can also be interpreted as a way of inheriting the local customs and developing regional distinctive features. There are more 
simulated subterranean buildings than the cliffside cave dwellings in Kangbaiwan mansion because of flexibility.

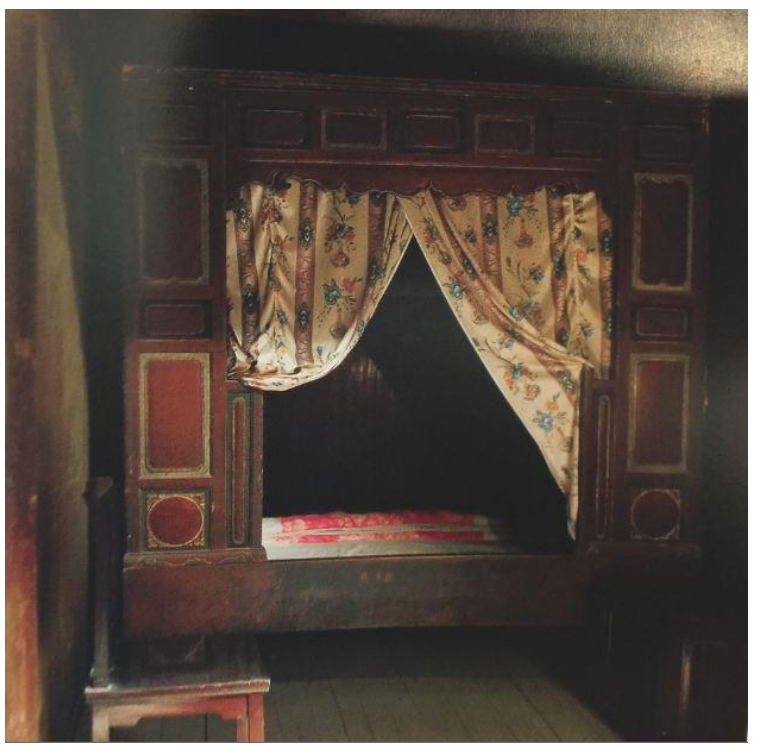

Figure 9. Elaborate alcove bed in Kangbaiwan Mansion [6]

\section{CONCLUSION}

To be part of the movement to seek sustainable development to our troubled earth, many things can be do in the field of sustainable architecture. Looking back into the past, historic and traditional architectures become a fertile source of new sustainable ideas.

From the discuss of the example of Kangbaiwan mansion, the key sustainable aspects can be summarized as follows:

1) The layout of the site plan is corresponding with the certain geographical environment in the first place.

2) The scale of the narrow courtyards strike a good balance between fulfilling the basic request of solar heating and limited mountainous building site.

3) The architecture typology of cave dwellings and the second-floor storage spaces are climatic adaptable, energy saving and a good strategy to improve the interior comfort of the main living spaces.
4) Adjusting measures to local conditions, such as local materials and techniques, is the effective way to save the construction cost as well as inherit the local culture.

\section{ACKNOWLEDGMENT}

This work was supported by a grant from China Scholarship Council.

\section{REFERENCES}

[1] Handbook of Green Building Design, and Construction, LEED, BREEAM, and Green Globes, Sam Kubba, 2012, pp. 1-2.

[2] J. Samadi, "Utilizing the central courtyard of traditional architecture in modern architecture," Electron Devices, vol. 6, no. 3, pp. 161-167, Mar. 2014.

[3] R. G. Knapp, Chinese Houses: The Architectural Heritage of a Nation, Hong Kong: Tuttle Publishing, 2005, p. 146.

[4] M. Zuo and X. Bai, Vernacular Dwellings in Henan Province, Beijing: China Building Industry Press, 2007.

[5] J. P. Liu, X. R. Zhu, L. Yang, and R. R. Hu, "Exemplary project of green cave dwellings in Loess Plateau," Electron Devices, vol. 4, no. 1, pp. 122-130, 2010.

[6] Ronald G. Knapp, Chinese Houses: The Architectural Heritage of a Nation, Hong Kong: Tuttle Publishing, 2005, pp. 151.

Xiaoqing A. Song was born in China in 1981, received her Bachelor Degree in architecture from Zhengzhou University, Henan Province, China, in 2005; and Master Degree in architecture from Xi'an University of Architecture and Technology, Shannxi Province, China, in 2008. She works in Zhongyuan University of Technology in Zhengzhou, China. From September 2015 to February 2016, she is working as a visiting scholar in Unitec Institute of Technology in Auckland, New Zealand. Her main publications are as follows: Architecture Preliminary (Beijing, China: China Building Materials Press, 2015). Her major field of interests are the protection of historic and traditional architecture as well as sustainable architecture.

Bin B. Su received his Master Degree and Doctor Degree in architecture from the University of Auckland in New Zealand. He is a Professor of Architectural Science, School of Architecture, Unitec Institute of Technology, Auckland, New Zealand.

His recent publications are as follows: Future Housing Energy Efficiency Associated with the Auckland Unitary Plan (Prague, Czech Republic: International Conference on Municipal Engineering, 2014); Indoor moisture control of Auckland houses with different ventilation systems (Dubai, United Arab Emirates: International Conference on Civil and Building Engineering, 2013). Prof. Su is the member of ASCE (American Society of Civil Engineers) and ASHRAE (American Society of Heating Refrigerating and Air-Conditioning Engineers). 